\title{
On the Scales of Selves: Information, Life, and Buddhist Philosophy
}

\author{
Carlos Gershenson ${ }^{1,2,3}$ \\ ${ }^{1}$ Instituto de Investigaciones en Matemáticas Aplicadas y Sistemas, \\ Universidad Nacional Autónoma de México, Mexico City, 01000, Mexico \\ ${ }^{2}$ Centro de Ciencias de la Complejidad, Universidad Nacional Autónoma de México, Mexico City, Mexico \\ ${ }^{3}$ Lakeside Labs GmbH, Lakeside Park B04, 9020 Klagenfurt am Wörthersee, Austria. \\ cgg@unam.mx
}

\begin{abstract}
When we attempt to define life, we tend to refer to individuals, those that are alive. But these individuals might be cells, organisms, colonies... ecosystems? We can describe living systems at different scales. Which ones might be the best ones to describe different selves? I explore this question using concepts from information theory, ALife, and Buddhist philosophy. After brief introductions, I review the implications of changing the scale of observation, and how this affects our understanding of selves at different structural, temporal, and informational scales. The conclusion is that there is no single "best" scale for a self, as this will depend on the scale at which decisions must be made. Different decisions, different scales.
\end{abstract}

\section{Information}

"In the long run, history is the story of information becoming aware of itself",

_James Gleick

Almost two decades ago, while reading Kauffman's Investigations (2000), I was struck when the challenge of describing information in terms of matter and energy was mentioned. In other words, how can we get meaning from physics? This has also been a central question in the origins of agency (Ruiz-Mirazo and Moreno, 2004; Barandarian, 2004; Barandiaran et al., 2009), autonomy (Maturana, 1999), individuality (Weber and Varela, 2002; Krakauer et al., 2020), and in a sense is also related with a problem of Cartesian dualism: how to relate mind and body (Clark, 1997). I began exploring the inverse route: what if instead, we describe matter and energy in terms of information? (Gershenson, 2012). This led me to learn about Wheeler's "it from bit" (1990). And as I began practicing Tibetan Buddhism, several similarities arose between the ideas I was developing and ancient teachings. Here I will relate ideas from information, (artificial) life, and Buddhist philosophy to discussions on self at different scales.

We can use the following notion of information that ex- tends the concept of Umwelt ${ }^{1}$ (von Uexküll, 1957): "Information is anything that an agent can sense, perceive, or observe." (Gershenson, 2012). This notion is in accordance to Shannon's measure (1948). It is general enough that it can be applied to matter, energy, organisms, and everything we can describe, since we are agents. "An agent is a description of an entity that acts on its environment" (Gershenson, 2007, p. 39). "The environment of an agent consists of all the information interacting with it." (Gershenson, 2012).

Describing the world in terms of information, we can explore questions on how agency and minds evolved, as we are not focussing on the substrate of agents or selves, including "laws" of information that apply to everything we can observe.

More recently, Stephen Wolfram has explored a similar approach, where starting with simple computational models (information), one can observe properties akin to those of fundamental physics (Wolfram, 2020) (space, time, energy, mass, relativity, gravity, and quantum mechanics). But how did life evolve out of physics?

\section{Life \\ "Life is understood backwards, but must be lived forwards" - Søren Kierkegaard}

There are so many definitions of life, but none that everyone agrees with (Bedau, 2008; Zimmer, 2021). Still, most would accept that living systems process information (Hopfield, 1994; Farnsworth et al., 2013). Thus, understanding information might improve our understanding of life (not implying that all information processing is related to life).

Certainly, the substrate of living systems is relevant, as it determines their functionalities. However, we can abstract the substrate and focus on the organization and properties of life. This was done already in cybernetics (Heylighen and Joslyn, 2001; Gershenson et al., 2014), but became central

\footnotetext{
${ }^{1}$ Umwelt means "environment" in German, and is used in ethology to refer to the world as perceived by different organisms.
} 
in artificial life (Langton, 1997; Aguilar et al., 2014). Since one of the goals of ALife is to understand the properties of living systems, it does not matter whether these are software simulations, robots, or protocells (representatives of "soft", "hard", and "wet" ALife).

In this context, we can define a "life ratio" as the amount of information of an agent produced by an itself over the amount of its information produced by its environment (Fernández et al., 2014). Actually, we can also use this as a measure of autopoiesis (Varela et al., 1974).

So, focussing only on the information of living systems, we can bridge different "implementations" of life with different substrates. In this same vein, we can ask questions about the nature of self in terms of information (see section below).

\section{Buddhist Philosophy}

"The world is given to me only once, not one existing and one perceived. Subject and object are only one.

The barrier between them cannot be said to have broken down as a result of recent experience in the physical sciences, for this barrier does not exist." - Erwin Schrödinger

I had the privilege of attending the tribute to Francisco Varela organized at the Sorbonne in Paris in $2004^{2}$. I learned a lot from his friends, students, and collaborators and the stories they shared. Varela was a late cybernetician in his early years and an early ALifer in his later years. He made important contributions related to autopoiesis, neurophenomenology, and more. He was a practicing Buddhist, and used his experience and also that of Buddhist monks, including the Dalai Lama, to study the mind (Varela and Poerksen, 2006). The conditions to delve into Buddhism came for me only in 2009.

I was raised in an atheistic environment, and I was never attracted to faith religions (Judaism, Christianism, Islam). However, I was never exposed to experience religions (Taoism, Buddhism, Hinduism), which have analogies with science (Nydahl, 2008). At least in the flavor of Buddhism I practice (Diamond Way), you are not expected to believe in the teachings. These are suggested to you, and it is up to you to see how and whether they work for you. One could say that Buddhism offers an empirical approach to spirituality, which has had its overlaps with cognitive science (Varela et al., 1991).

Three approaches (yanas, paths, or vehicles) can be identified in Buddhism (each represented by a variety of schools), each one building on the previous ones:

\footnotetext{
${ }^{2}$ Audio recordings of most talks are available at http: //turing.iimas.unam.mx/ comdig/webcasts/ Varela04/
}

1. Hinayana (narrow path) or Theravada (Gombrich, 2006) focusses on seeking individual happiness and end our own suffering, mainly through introspection.

2. Mahayana (great path) (Williams, 2008) notices that all beings suffer but want to experience happiness, so one also focusses on helping others, balancing wisdom and compassion (Germer and Siegel, 2012).

3. Vajrayana (diamond path) (Nydahl, 2011; Leonteva, 2013) notes that in order to help all beings, we must first be enlightened, so the focus is on approaching "enlightenment" (even if this might be better seen as an infinite game (Sinek, 2019)).

We can say that each yana has a distinct perspective of self, and focusses at a different scale: Hinayana on the individual, Mahayana on others (up to all beings), and Vajrayana goes beyond distinctions (highest scale).

There are different ways to describe enlightenment. But before enlightenment, we first must be "liberated", from our "disturbing emotions" (ignorance, attachment, anger, pride, jealousy, and their combinations). Liberation is not about ignoring emotions, but not letting them guide your actions (body), words (speech), nor thoughts (mind). Free from disturbing emotions and stiff ideas, we are able to develop and gradually approach enlightenment.

One form of enlightenment is realizing that the ego (self) is just an illusion. Another is understanding that the observer (self), observed (environment), and action of observing are not separable (Nydahl, 2008). The object requires a subject to perceive it, while the subject requires an object to ground its perception. And of course this requires the perceptive action, so confusion tends to arise when we attempt to separate subject, object, and action. As Humberto Maturana argued ${ }^{3}$, every living organism arises within a niche that sustains it, leading to an organism-niche ecological unit.

One Buddhist teaching says "form is emptiness, emptiness is form". This could be understood in the following way: if we take any object, and remove all of its properties or components, only emptiness remains. This emptiness is not sterile, but precisely the opposite. Since everything "leaves behind" this same emptiness, any form arises from emptiness. Another way of seeing this is understanding space as potential (for Wolfram (2020), space seems to be the basis of fundamental physics). In this context, space can also be seen as information, and thus, information as potential (Gershenson, 2012). Therefore, one bit is not a one or a zero, but the potential of being one or zero. Then, a string of bits is not an arbitrary sequence of ones and zeros, but the potential of any sequence of ones and zeros.

\footnotetext{
${ }^{3}$ At the 2014 Congress of the World Organisation of Systems and Cybernetics in Ibagué, Colombia.
} 
Buddhism teaches how to perceive and think things in the "best" possible way ${ }^{4}$, but not necessarily how to do things in the best possible way. We still need common sense and science for that.

\section{Scales}

\section{“All scales are relevant."}

Information about the same phenomenon will change at different scales (Bar-Yam, 2004) or levels of abstraction (Gershenson, 2002a). For example, at the molecular scale, one requires more information to describe a human than at the cellular scale, than at the animal scale, than at the social scale, than at the ecosystem scale, than at the biosphere scale.

If we extrapolate, at the "lowest" scale (whatever that might be) we would require infinite information to describe any phenomenon. At the "highest" scale, we would require no information, as everything is contained (Gershenson, 2012) (this highest scale is actually analogous to the highest view of Buddhist teachings). As shown in Figure 1 , at the highest scale everything is included (form is emptiness), while at the lowest scale, everything is possible (emptiness is form).

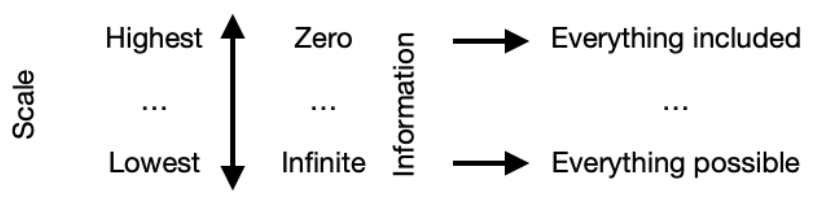

Figure 1: Different scales of description require different amounts of information (Gershenson, 2020): higher scales, less information.

In Buddhism, the Dharmakaya (truth state) could be understood as perceiving things at the highest scale. Since everything is contained at that scale, change, distinctions, and differences disappear, so just "the way things are" is already a truth (tautology). It is only when we introduce distinctions at lower scales (for which we require more information), that conflicts may appear. One of these distinctions that we tend make constantly is that between ourselves and our environment. Well, it is embedded in our language, as we distinguish between first person and second/third persons.

What might be the best scale to describe selves and ourselves?

\section{Selves}

"The aim of science is not things themselves,

\footnotetext{
${ }^{4}$ When enlightened, "everything happens as it should".
}

\section{as the dogmatists in their simplicity imagine, but the relations among things; outside these relations there is no reality knowable." - Henri Poincaré}

Traditionally, the biological self has been attempted to be defined molecularly (Varela et al., 1974), at the cellular level (De Duve, 2003). Cognition has been studied mainly at the organism (multicellular) level (Wilson and Keil, 1999), although some species, such as ants, can be considered to have a "self" at the group level (Hölldobler and Wilson, 2008). Immunology has also studied the self, since the immune system has to distinguish between "self" and "other" (Cohen, 2000). It should also be noted that considerable parts of chemistry deal with molecules that occur only because of living systems. I would argue that this is an example of downward causation (Campbell, 1974; Gershenson, 2021).

We could say that ALife, especially "soft" ALife, has defined selves in terms of information. For example, in the Game of Life (Berlekamp et al., 1982), gliders can be described and studied as cognitive entities (Beer, 2014).

We have mentioned already selves at different structural scales: cells, tissues, organs, organisms, groups, societies, nations, species, biospheres... At each of these scales, we can study purpose, goals, agency, individuality, and cognition (Levin and Dennett, 2020), that could even be studied at lower scales (Gershenson, 2004). Also, it can be said that evolution and selection act at different scales (Michod, 2000; Penn, 2005). Moreover, selves at different scales can affect each other. Upward causation is clear, but for some reason, downward causation seems to be forgotten, even when it is also relevant (Campbell, 1974; Bitbol, 2012; Walker, 2014; Flack, 2017). For example, we follow social norms. These are imposed from the social scale to the individual scale, constraining and promoting individual behaviors. Our microbiome affects us, but we also affect our microbiota. Also, are our microbes part of our self?

At each structural scale, cooperation tends to be easier "within" selves, while conflict is easier to occur between selves. Metasystem transitions (Turchin, 1977; Maynard Smith and Szathmáry, 1995) show how evolution has managed to mediate conflicts between selves at different scales (Michod, 2003), in order to organize selves at higher scales. It makes sense: the best way to end competition is to merge with your competitors. Of course, this is easier said than done, as we can observe plenty of conflict at all scales, where different selves fight for themselves.

We can identify also selves at different temporal scales. In our experience and in our passports, we are the same selves than the ones we were the day we were born, but our components are in a constant flux. Are we the same selves? It depends at which scales we observe: some of "our" molecules might change with every breath, some of our cells (e.g., neutrophils) change within days, while some 
of our memories can last our lifetime. What is maintained is our organization, that can be represented in terms of information.

We can also consider selves at different informational scales. Depending on how detailed we describe ourselves, we might be changing constantly (flux of matter, energy, and information). Or we might not change at all (I am still Carlos). If we lose even more details (information), then we lose distinctions between individuals, so we can put in the same category, e.g., all Mexicans, all humans, all animals, all selves.

Notice that structural and temporal scales can be seen as particular types of informational scales, where we simply add or remove information to go to more particular or abstract descriptions of phenomena.

My personal interpretation of reincarnation is the following: if we can abstract details of ourselves, then different "instances" will fall within the same "category" (self). So, just like we can abstract all people born in a certain year into a category, we can abstract people with similar personalities into a single category. So, if we find someone that reminds us of someone else who already died, we can consider them to be "in the same category". This does not imply that when we die something physically goes from our dead bodies into a newborn. It is simply that similar characteristics can be found in different people. For example, we can have four apples and four pears. Different instances, but four all the same.

We can see that the separation (categorization) of selves from their environment is artificial. But there will always be interactions, i.e., complexity (Gershenson and Heylighen, 2005; Heylighen et al., 2007; Gershenson, 2013; De Domenico et al., 2019)). At any scale, except at the highest, we will be leaving "something out" of a description. But the highest scale is not always practical. We need to make distinctions to take decisions. Well, these decisions must be made at a particular scale. Thus, we can conclude that the best scales of description of selves will be those at which decisions are made. Different decisions, different scales. If the decisions is about our biosphere, we should forget about our individuality. But if we are hungry, we must focus on sustaining our decaying bodies.

The same applies to purpose and goals (Rosenblueth et al., 1943). The best scales to describe systems are those at which purpose and goals are identified.

\section{Conclusion}

Selves are arbitrary. They depend on the scale at which they are described. This does not mean that all scales nor all selves are equally valid. Some are more useful than others. However, this usefulness is context-dependent (Gershenson, $2002 b$ ). This is related to the problem of defining the boundaries of a system. In some contexts, it might be better to focus on selves at the cellular level, in others, at the organ- ismal level, in others, at the societal level, in others, at the biospheric level. So we cannot say which scale of self is "better" independent of a context. Thus, we might be better off considering the potential of having different selves at different scales. Like this, we can compare many possibilities, but focus on particularities when necessary. This is similar to Buddhist teachings, so it is not something entirely novel, although it took quite an ideological journey across millenia to be able to express it in this way, and to apply it in novel contexts.

\section{Acknowledgements}

I thank Olaf Witkowski for motivating me to write this essay and three anonymous referees for useful comments. Support from UNAM's PAPIIT projects IN107919 and IV100120 was received.

\section{References}

Aguilar, W., Santamaría Bonfil, G., Froese, T., and Gershenson, C. (2014). The past, present, and future of artificial life. Frontiers in Robotics and AI, 1(8).

Bar-Yam, Y. (2004). Multiscale variety in complex systems. Complexity, 9(4):37-45.

Barandarian, X. (2004). Behavioral adaptive autonomy. a milestone in the ALife route to AI? In Pollack, J., Bedau, M., Husbands, P., Ikegami, T., and Watson, R. A., editors, Artificial Life IX Proceedings of the Ninth International Conference on the Simulation and Synthesis of Living Systems, pages 514-521. MIT Press.

Barandiaran, X., Di Paolo, E. A., and Rohde, M. (2009). Defining agency: Individuality, normativity, asymmetry, and spatiotemporality in action. Adaptive Behavior, 17(5):367-386.

Bedau, M. A. (2008). What is life? In Sahotra, S. and Plutynski, A., editors, A Companion to the Philosophy of Biology, pages 455-471. Blackwell Publishing Ltd.

Beer, R. D. (2014). The cognitive domain of a glider in the game of life. Artificial Life, 20(2):183-206.

Berlekamp, E. R., Conway, J. H., and Guy, R. K. (1982). Winning Ways for Your Mathematical Plays, volume 2: Games in Particular. Academic Press, London.

Bitbol, M. (2012). Downward causation without foundations. Synthese, 185(2):233-255.

Campbell, D. T. (1974). 'Downward causation' in hierarchically organized biological systems. In Ayala, F. J. and Dobzhansky, T., editors, Studies in the Philosophy of Biology, pages 179186. Macmillan.

Clark, A. (1997). Being There: putting brain, body, and world together again. MIT Press, Cambridge, MA.

Cohen, I. R. (2000). Tending Adam's Garden: Evolving the Cognitive Immune Self. Academic Press, London. 
De Domenico, M., Camargo, C., Gershenson, C., Goldsmith, D., Jeschonnek, S., Kay, L., Nichele, S., Nicolás, J., Schmickl, T., Stella, M., Brandoff, J., Salinas, Á. J. M., and Sayama, H. (2019). Complexity explained: A grassroot collaborative initiative to create a set of essential concepts of complex systems. https://complexityexplained.github.io.

De Duve, C. (2003). Live Evolving: Molecules, Mind, and Meaning. Oxford University Press.

Farnsworth, K. D., Nelson, J., and Gershenson, C. (2013). Living is information processing: From molecules to global systems. Acta Biotheoretica, 61(2):203-222.

Fernández, N., Maldonado, C., and Gershenson, C. (2014). Information measures of complexity, emergence, selforganization, homeostasis, and autopoiesis. In Prokopenko, M., editor, Guided Self-Organization: Inception, volume 9 of Emergence, Complexity and Computation, pages 19-51. Springer, Berlin Heidelberg.

Flack, J. C. (2017). Coarse-graining as a downward causation mechanism. Philosophical Transactions of the Royal Society A: Mathematical, Physical and Engineering Sciences, 375(2109):20160338.

Germer, C. K. and Siegel, R. D., editors (2012). Wisdom and compassion in psychotherapy: Deepening mindfulness in clinical practice. The Guilford Press.

Gershenson, C. (2002a). Complex philosophy. In Proceedings of the 1st Biennial Seminar on Philosophical, Methodological and Epistemological Implications of Complexity Theory, La Habana, Cuba.

Gershenson, C. (2002b). Contextuality: A philosophical paradigm, with applications to philosophy of cognitive science. POCS Essay, COGS, University of Sussex.

Gershenson, C. (2004). Cognitive paradigms: Which one is the best? Cognitive Systems Research, 5(2):135-156.

Gershenson, C. (2007). Design and Control of Selforganizing Systems. CopIt Arxives, Mexico. http://tinyurl.com/DCSOS2007.

Gershenson, C. (2012). The world as evolving information. In Minai, A., Braha, D., and Bar-Yam, Y., editors, Unifying Themes in Complex Systems, volume VII, pages 100-115. Springer, Berlin Heidelberg.

Gershenson, C. (2013). Facing complexity: Prediction vs. adaptation. In Massip, A. and Bastardas, A., editors, Complexity Perspectives on Language, Communication and Society, pages 3-14. Springer, Berlin Heidelberg.

Gershenson, C. (2020). Information in science and Buddhist philosophy: Towards a non-materialistic worldview. In Alekseyev-Apraksin, A. M. and Dronova, V. M., editors, Vajrayana Buddhism in Russia: Topical Issues of History and Sociocultural Analytics, pages 210-218. Almazny Put, Moscow, Russia.

Gershenson, C. (2021). Emergence in artificial life. arXiv:2105.03216.
Gershenson, C., Csermely, P., Erdi, P., Knyazeva, H., and Laszlo, A. (2014). The past, present and future of cybernetics and systems research. systema: connecting matter, life, culture and technology, 1(3):4-13.

Gershenson, C. and Heylighen, F. (2005). How can we think the complex? In Richardson, K., editor, Managing Organizational Complexity: Philosophy, Theory and Application, chapter 3, pages 47-61. Information Age Publishing, Greenwich, CT, USA.

Gombrich, R. F. (2006). Theravada Buddhism: A social history from ancient Benares to modern Colombo. Routledge, 2nd edition.

Heylighen, F., Cilliers, P., and Gershenson, C. (2007). Complexity and philosophy. In Bogg, J. and Geyer, R., editors, Complexity, Science and Society, pages 117-134. Radcliffe Publishing, Oxford.

Heylighen, F. and Joslyn, C. (2001). Cybernetics and second order cybernetics. In Meyers, R. A., editor, Encyclopedia of Physical Science and Technology, volume 4, pages 155-170. Academic Press, New York, 3rd edition.

Hölldobler, B. and Wilson, E. O. (2008). The Superorganism: The Beauty, Elegance, and Strangeness of Insect Societies. W. W. Norton \& Company.

Hopfield, J. J. (1994). Physics, computation, and why biology looks so different. Journal of Theoretical Biology, 171:5360 .

Kauffman, S. A. (2000). Investigations. Oxford University Press, Oxford, UK.

Krakauer, D., Bertschinger, N., Olbrich, E., Flack, J. C., and Ay, N. (2020). The information theory of individuality. Theory in Biosciences, 139(2):209-223.

Langton, C. G. (1997). Artificial life: An overview. MIT Press.

Leonteva, L. (2013). Marpa the translator. Buddhism Today, 31

Levin, M. and Dennett, D. C. (2020). Cognition all the way down. Aeon.

Maturana, H. R. (1999). The organization of the living: A theory of the living organization. International Journal of HumanComputer Studies, 51(2):149-168.

Maynard Smith, J. and Szathmáry, E. (1995). The major transitions in evolution. Oxford University Press.

Michod, R. E. (2000). Darwinian Dynamics: Evolutionary Transitions in Fitness and Individuality. Princeton University Press, Princeton, NJ.

Michod, R. E. (2003). Cooperation and conflict mediation during the origin of multicellularity. In Hammerstein, P., editor, Genetic and Cultural Evolution of Cooperation, chapter 16, pages 261-307. MIT Press, Cambridge, MA.

Nydahl, O. (2008). The Way Things Are: A Living Approach to Buddhism for Today's World. O Books, London.

Nydahl, O. (2011). The Great Seal: Limitless Space \& Joy: The Mahamudra View of Diamond Way Buddhism. Firewheel Publishing. 
Penn, A. (2005). Ecosystem selection: Simulation, experiment and theory. $\mathrm{PhD}$ thesis, University of Sussex, Brighton, UK.

Rosenblueth, A., Wiener, N., and Bigelow, J. (1943). Behavior, purpose and teleology. Philosophy of Science, 10(1):18-24.

Ruiz-Mirazo, K. and Moreno, A. (2004). Basic autonomy as a fundamnental step in the synthesis of life. Artificial Life, 10(3):235-259.

Shannon, C. E. (1948). A mathematical theory of communication. Bell System Technical Journal, 27(3 and 4):379-423 and 623-656.

Sinek, S. (2019). The Infinite Game. Portfolio.

Turchin, V. (1977). The Phenomenon of Science. A Cybernetic Approach to Human Evolution. Columbia University Press, New York.

Varela, F. J., Maturana, H. R., and Uribe., R. (1974). Autopoiesis: The organization of living systems, its characterization and a model. BioSystems, 5:187-196.

Varela, F. J. and Poerksen, B. (2006). Truth is what works: Francisco j. varela on cognitive science, buddhism, the inseparability of subject and object, and the exaggerations of constructivism-a conversation. The Journal of Aesthetic Education, 40(1):35-53.

Varela, F. J., Thompson, E., and Rosch, E. (1991). The Embodied Mind: Cognitive Science and Human Experience. MIT Press, Cambridge, MA.

von Uexküll, J. (1957). A stroll through the worlds of animals and men. In Schiller, C. H., editor, Instinctive Behavior: The Development of a Modern Concept, pages 5-80. International Universities Press, New York.

Walker, S. I. (2014). Top-down causation and the rise of information in the emergence of life. Information, 5(3):424-439.

Weber, A. and Varela, F. J. (2002). Life after kant: natural purposes and the autopoietic foundations of biological individuality. Phenomenology and the Cognitive Sciences, 1:97-125.

Wheeler, J. A. (1990). Information, physics, quantum: the search for links. In Zurek, W. H., editor, Complexity, Entropy, and the Physics of Information, volume VIII of Santa Fe Institute Studies in the Sciences of Complexity. Perseus Books, Reading, MA.

Williams, P. (2008). Mahayana Buddhism: the doctrinal foundations. Routledge, 2nd edition.

Wilson, R. A. and Keil, F. C., editors (1999). The MIT Encyclopedia of the Cognitive Sciences. MIT Press, Cambridge, MA.

Wolfram, S. (2020). A class of models with the potential to represent fundamental physics. Complex Systems, 29(2):107-536.

Zimmer, C. (2021). Life's Edge: The Search for What It Means to Be Alive. Dutton. 